\title{
Heidegger y el Humanismo
}

\author{
JOSÉ LUIS MOLINUEVO \\ Universidad de Salamanca
}

La Carta sobre el Humanismo ha sido, desde su publicación, uno de los «mojones» ineludibles para los estudiosos, peregrinos, o simplemente curiosos del «camino del pensar» de Martin Heidegger. Hace falta estar en alguna de esas situaciones para explicar una lectura detenida, y en ocasiones repetida, de una obra que, por lo demás, no ha gozado de especial interés para los historiadores interesados en la temática a la que parece aludirse en el título. Esta afirmación puede parecer excesiva, y requiere algunas precisiones: si nos acogemos a la autointerpretación que ahí propone Heidegger, a esa lectura interna dirigida a salvar la continuidad, se nos aparece un pensamiento intemporal del que sólo cumple reflejar sus variaciones topológicas en (sobre) lo mismo; la "Kehre», el giro, cabría sólo entenderlo en el ámbito poético de la danza del Ser, algo tampoco desdeñable en su continuación postmoderna. Pero si alguien quiere, sin dejar de tener en cuenta la autointerpretación, aunque en contra de los principios metodológicos de Heidegger, hacer también una historia externa, entonces se encuentra ante la penosa tarea de no sólo revisar la continuidad de un pensamiento, sino, y sobre todo, de problematizar la mayor parte de las claves del mismo que hasta ahora se nos han ofrecido. No es, por otra parte, una labor de deconstrucción radical, sino el ensayo de un difícil camino intermedio, en el que, por ejemplo, el tema de las relaciones entre filosofía y política podía dar algo más de sí que una reyerta terapéutica generacional.
Hay otra razón, la más importante, de la perplejidad de los historiadores ante el escrito: contra lo que el título sugiere, en él se habla poco del Humanismo. No es grave, y ya estamos acostumbrados a ello en otras publicaciones, pero sí lo es lo mucho que en lo poco se dice aquí. Además, la postura de Heidegger revela un "exceso de conciencia histórica", que, paradójicamente, en su interpretación metafísica o epocal del Ser, amenaza, lejos de posibilitarla, a la historia misma. Es signo, o destino, de la orfandad filosófica posthegeliana el recurrir sistemáticamente a la historia para tratar los problemas del presente, pero sin pasar por ella y sin mirar tampoco alrededor. En esto hay una curiosa coincidencia entre los heideggerianos actuales y los seguidores de la última fase de la Teoría Crítica, tal como la expusieron sus fundadores. A algunos de estos temas, demasiados, quisiera referirme en esta breve nota.

Heidegger señala agudamente que en la pregunta de Beaufret, ¿cómo dar un nuevo sentido a la palabra Humanismo?, subyacen dos supuestos: que el Humanismo ha perdido su sentido $y$ que merece la pena volver a dárselo. Afirmará decididamente lo primero, pero no verá la necesidad de lo segun. do. Piensa que la explicación de la pérdida de vigencia del Humanismo está ya en su propia naturalcza, que lleva aparejada la decadencia y la publicidad: todo "ismo" surge por debilita. miento del pensar originario que ha 
perdido fuerza por alejarse de su elemento, el pensar del Ser. Se convierte entonces en filosofía, en una ocupación, en una profesión, que necesita del lenguaje sólo como instrumento de intercambio e información de los saberes académicos ya tecnificados.

El alejamiento del pensar originario se produce al tener como centro de su interés la esencia del hombre, por lo que éste se convierte en lo esencial del pensamiento. El Humanismo está así radicado, para Heidegger, en la metafísica de la subjetividad, propia de la época moderna, y todavía presente en nuestros días. Lo distintivo de ella es el olvido del Ser por el predominio del sujeto desde cuya razón se proyecta el Ser del ente. Por eso, el Humanismo se remite en sus sucesivos renacimientos a esa tradición romana, y en último término griega, para la que el ser del hombre es algo evidente, concibiéndolo como "animal racional». Pero Heidegger subraya que interpretarle como "animal», además de atentar contra su "dignidad", significa sumirle en una indiferenciación ontológica respecto a los otros entes, caer en un biologismo que desconoce cómo los animales pueden estar en un entorno, pero no tener mundo ni lenguaje, ya que no son «eksistencias", es decir, no están abiertos ni permanecen en la verdad del Ser. El distintivo de "racional" no elevaría, sino que limitaría todavía más al hombre en el privilegio de una de sus facultades. La "humanitas" es el substrato metafísico de la modernidad, entendida como imperio del principio de razón que se consuma en la técnica, el auténtico nihilismo.

Desde esta perspectiva, el Humanismo histórico no es, para Heidegger, sino el pretexto de recurrencia a una historia más originaria, la del Ser, en la que se ve su necesidad, $y$, al mismo tiempo, la llegada de su final. En su particular concepción de la "Reiteración " (Wiederholung), de las preguntas que subyacen a la modernidad, no cabe ni la repetición ni la recuperación de sus momentos en cuanto tales, sino como presencia que reclama una ausencia, antes la de la ontología fundamental, y ahora la del pensamiento del Ser. La "humanitas" puede ser reintcrpretada como "Sorge" o "Existenz" (o Ek-sistenz), pero ello traería nuevamente los problemas que plantea el lenguaje metafísico de la subjetividad, y que lastraron la comprensión y la continuidad de Ser y Tiempo. Porque, en definitiva, el nudo gordiano no está en las discusiones o distinciones acerca de la esencia o existencia del hombre, sino, como se lo plantea a Sartre, de si es primero el Ser o el hombre. Ahí está la verdadera objeción al Humanismo, y en último término a su versión existencialista; la razón de que Heidegger no vea la necesidad de su recuperación $\mathrm{y}$, todavía más, le horrorice ser confundido y llamado existencialista. Pero, antes de pasar más adelante, convendría hacer unas precisiones a lo ya expuesto de Heidegger sobre el Humanismo.

$* * *$

La visión que Heidegger tiene del Humanismo hay que situarla en un doble contexto: el propiamente histórico y en el ámbito de la historia del Ser. Fácilmente se puede subsumir el primero en el segundo, pero si esto ayuda a comprender mejor a Heidegger, no ocurre lo mismo con el tema de que se trata. Las referencias históricas que hace del Humanismo, lo sitúan dentro de la historia de la modernidad. La lectura que hace de esta época tiene un carácter unitario y lineal, deudor de un esquema idealista que es, precisamente, el 
que quiere combatir en otros aspectos dentro de su obra. Más en concreto: sigue la imagen ilustrada, reapropiada por la historiografía alemana en este punto, de que el Renacimiento (en particular el italiano) no tiene un valor filosófico sustantivo, limitándose a una recuperación en los campos de la historia y las letras de la Antigüedad clásica. El origen de la modernidad filosófica habria que situarla en la obra de genios aislados, por ejemplo Descartes, a los que ha dedicado particular atención. El condensaría esta época de la imagen del mundo, es decir, del mundo como imagen.

Desde el punto de vista historiográfico, esta lectura se sitúa también en la reivindicación que hicieron ya los alemanes de sus propios antecedentes, y que les lleva a oponer su Reforma, la filosofía de la naturaleza y, sobre todo, la mística, frente al Renacimiento. Esta reacción es comprensible, como también la polémica que se ha desarrollado desde comienzos del siglo xx. Pero lo que resulta más problemático es el empobrecimiento histórico y filosófico que sufre la imagen de la modernidad en su conjunto leída en clave idealista. Esto nos lleva a una paradoja, no extrana cuando se pierden los referentes históricos más elementales: a una interpretación metafísica de la modernidad, para así mejor poder rechazarla, que lleva también anejo un repudio del historicismo, denostado hoy por tirios y troyanos, cayendo en los mismos errores que se le imputan. No resulta esto extraño, si se considera que también se hace una lectura metafísica del historicismo, olvidando que, al igual que otros «ismos» y la propia modernidad, se declina en plural. La comprensión de la complejidad de lo contemporáneo no pasa, ciertamente, por la simplificación en la interpretación de lo moderno.
Un especialista en el Humanismo, y no sospechoso precisamente de ser antiheideggeriano, Ernesto Grassi, ha subrayado, en su trabajo «La tesis heideggeriana del fin de la filosofía y la tradición humanístican, lo inexacto de esta interpretación de la modernidad. Al menos en este trabajo, junto a ello, se esfuerza en mostrar el paralelismo que hay entre el humanismo no neoplatónico y las tesis de Heidegger sobre el Ser y el lenguaje. En otros, por ejemplo «Humanismo y marxismo", el paralelismo ya no se ve tan claro, y me atrevería a decir que pueden sacarse consecuencias bien distintas de la anteriormente mencionada. La tesis de Grassi es sugerente por lo que contribuye a presentar una nueva imagen del Humanismo, y obtiene una confirmación en la lectura detenida de los textos. Según ella, en los humanistas no habría sólo una crítica cerrada del medievo y una recuperación acrítica y servil de lo clásico. La auténtica aportación de los humanistas a la filosofía consistiria en su propuesta de concebir la filología como una nueva visión del hombre. La frase de Aristóteles que le caracteriza como "zoon logon ejon", no tendría así la traducción de «animal racional\%, sino todo lo contrario, como el ser que tiene la palabra, y yendo más lejos, como "el ser que es tenido por la palabra». La filología es amor al logos, pero entendido éste como la esencia del hombre, ya que le abre a su mundo y a su historia. La pluralidad significativa de la palabra, junto con la evolución semántica, le revelan al hombre su propia historicidad y la complejidad de lo real. Si prefieren llamarse gramáticos o retóricos, por contraposición a la filosofía del medievo, no es porque abominen de la filosofía, sino de esa filosofía que no tiene en cuenta lo individual y sólo desarrolla la razón, como 
también lo harán en fases más tardias los filósofos modernos.

Este no es, pues, un humanismo que tenga su continuidad en la tópica ilustrada, pero que sí está presente a lo largo de toda la modernidad. No deja de tener su pensamiento un carácter original, porque se haya preocupado desde el comienzo en tender un puente entre lo abstracto y lo concreto. No deja el problema de la ética y de la sociedad para un después que nunca llega o lo hace en las brumas difusas de la ideología. La retórica presupone en ellos la unión entre el arte del bien decir y hacer, va dirigida a la totalidad del hombre, que no es sólo razón sino también sentimiento. La primacía de las «litterae" tiene su sentido cuando parte de un pensamiento que surge $y$ va dirigido a las cosas, del mismo modo que la ética es entendida como jurisprudencia, es decir, de una ayuda para el hombre que sólo se entiende como ser social. Pero esta dimensión individual, histórica y social sólo se le abre al hombre a través del lenguaje. El logos, como englobante de la totalidad del hombre, aparece tambićn opuesto a lo que se entiende como racionalidad instrumental y limitativa de las ciencias. Nuevamente, no por un espíritu anticientífico, sino por lo que puede tener de cultivo, en algunos casos, unilateral de lo humano.

La sugerencia de Grassi consiste, pues, en no leer sólo el Humanismo en clave neoplatónica. Pero quizá sea también interesante subrayar otro aspecto descuidado al tratar el tema del Humanismo. Heidegger parece centrar la consideración humanista del hombre en torno a su «dignidad", lo que le permitiría seguir una continuidad en la Ilustración y el Romanticismo. Y repite que su rechazo del Humanismo no quiere significar que vaya contra ella, o que en su propio pensamiento no pue- da alcanzar la "humanitas" la verdadera dignidad. Frente a estas salvedades, seria también interesante señalar que otros humanistas no han tenido reparos en tratar el tema de la «indignidad"como perteneciente también a la "esencia" del hombre. Se puede acudir a Pérez de Oliva, que, en su eclecticismo, contrapunto de Pico, subraya la desventaja del hombre respecto al animal, de un entendimiento que nos ha sido dado más para comprender nuestras miserias que para remediarlas; a un Erasmo que en la comedia de la vida preconiza su goce desde el amor propio; a Francisco Sánchez o el escepticismo cartesiano de la ignorancia no socrática; y a Montaigne, en quien encontramos los rasgos modernos del «anarca».

$$
\text { *** }
$$

En el ámbito de la historia del Ser, observa Heidegger, si se decide a mantener la palabra Humanismo, ésta adquiere un sentido "extraño". Porque recuperarlo, admitiendo su terminología, diciendo que la esencia del hombre consiste en su "ek-sistencia", significa ciertamente dotarla de una «dignitas» extraña, la de que la esencia del hombre es esencial para el Ser, pero entonces ya no es lo más importante, ya no es el "sólo hay hombre" (Sartre), sino que tampoco importa sólo a los hombres en cuanto tales, ya que «sólo hay Ser». La plasticidad ilimitada del Humanismo neoplatónico, esa libertad para el infinito, se trasmuta aquí en libertad para el Ser, pero bajo otra categoría «extraña», la de "destino", quizá el concepto fundamental de la "Carta". El hombre ha sido "arrojado" por el Ser en la verdad del Ser, para que, ek-sistiendo así, "cuide" la verdad del Ser, en un pensar del Ser que es acontecimiento y res- 
puesta, para que pueda en la verdad del Ser aparecer el ente en cuanto tal. El hombre ya no es "el Señor del ente", sino «el pastor del Ser». El quehacer del pensar consiste, pues, en traer a lenguaje el Ser, y de este modo el lenguaje es "la casa del Ser».

El «es gibt Sein» de Heidegger no quiere expresar una facticidad, sino la identidad de lo mismo en la donación que crea el lugar de lo abierto, de su verdad, y de su ocultación en el olvido de la metafísica. El darse del Ser abre una historia como destino, en la que acontece el pensar del Ser, es decir, la $e k$-sistencia humana. El hombre no crea la historia, ni decide sobre ella, sólo le compete preguntarse si su esencia está adecuada a su destino. El pensar esencial es el intento de corresponder a esa donación. No tiene un carácter activo en el sentido de efectividad y sus resultados son inciertos.

Se ha subrayado el componente teológico del pensamiento de Heidegger, a pesar de que él confina a la teología dentro de las ciencias, por tratar de un ente, Dios; también se ha detectado una difusa religiosidad que va desde el desencanto epocal, la ética protestante, al tono enfático y la tradición predicadora de los grandes idealistas alemanes (Fichte); $\dot{y}$, más recicntemente, entre nosotros, se estima una cierta devoción "mariana" en la "piedad del pensamiento", propia de las gentes sencillas e ignorantes, los "pastores» por ejemplo, no los torturados y retorcidos metafísicos; de este modo, el tiempo ekstático se convertiría en un etemo mayo en el que el pensador ofrece los juegos florales del lenguaje al Ser.

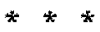

Afirma Heidegger que «todavía espera el Ser que él mismo sea digno de pen- sar para el hombre», y que para que los contemporáneos podamos estar en la dimensión de la verdad del Ser, es necesario poner antes en claro en qué medida al hombre le importa el Ser y en qué medida éste le reclama.

Vattimo ha señalado a la Carta sobre el Humanismo como "el escrito que inaugura la conciencia contemporánea de la crisis del Humanismon. Esa crisis es la misma que la de la metafísica, ya que consiste tanto en la caída del sujeto como «autoconciencia» como la de su fundamento, el ser-presencia. Heidegger habría intentado pensar el Ser más allá de las relaciones entre sujeto y objeto, de fundamento que no se diferencia de lo fundado, en una nueva dimensión del tiempo. $Y$ en ese intento, después de la inflexión que significa la "Kehre», es capital, para él, y todavía más para Vattimo, la influencia de Nietzsche. Porque, en un primer momento, Vattimo interpreta a Nietzsche a través de Heidegger y posteriormente a Heidegger a través de Nietzsche. Esto significa algo más que una cuestión de hermenéutica tradicional, porque va a propiciar las dos salidas que propone a su crítica de la modernidad. Así, Nietzsche habría conectado la crisis del Humanismo con la muerte de Dios, el fundamento al que se sujeta el sujeto, por lo que «es también el primer pensador radical no humanista de nuestra época». Aunquie es cierto que esto queda matizado en Vattimo cuan. do la voluntad de poder ve también la presencia del Humanismo, en forma de metafísica consumada.

Pero si Vattimo está de acuerdo en el análisis de la modernidad como época del sujeto en sentido "fuerte», y en la que lo moderno se convierte en valor (lo nuevo como valor, el valor de lo nuevo), las diferencias empiezan a notarse cuando se plantea la pregunta de qué 
pensar y cómo después de la modernidad.

El tema sigue siendo el Ser, pero sometido ahora a un proceso de historicización después de las tendencias disolutivas de la dialéctica. Es decir, que el Ser ya no es lo originario, ni el fundamento, sino que «acontece». Pero en Vattimo esta expresión quiere decir, coincidiendo con Heidegger, que no es la presencia constante, que no puede ser interpretado desde el presente. Luego el Ser es lo sido, aquello que se desvanece y deja su huella en los entes. El Ser se disuelve en la historia, que tampoco se configura ya desde un centro, sino en unidades de tiempo. La perspectiva ya no es tanto la de la identidad sino la de la diferencia. Ser no es identidad vacía, sino situación, historicidad. Vattimo no quiere caer con ello en lo que denomina como la tragedia neoexistencialista, que busca sentido donde desespera de hallarlo. Propone vivir positivamente la pérdida de sentido, y convertirlo en hilo conductor de la historia. Vivir el nihilismo como una "chance", levantar un acta notarial de la crisis de la modernidad, en el sentido de vivirla como hilo conductor que nos lleva a lo contemporáneo. De este modo, la historia sólo tendrá sentido cuando se haya disuelto en nosotros. Ahí se inserta el pensamiento de la diferencia: porque el Ser no es, sino que sólo son los entes, y en tanto acaece, o acontece en los entes. Una ontología débil mostraría cómo se ha ido disolviendo (historia) ese ser presencia, estabilidad, del que sólo nos queda su ruina, el ser como monumento, recuerdo, tradición.

Esto significa para Vattimo que, si en la lectura heideggeriana de la modernidad, el humanismo y la metafísica han acabado en la técnica, ésta, como "Ge-stellt" (prefiere traducir «imposi- cións), no debe interpretarse desde los habituales lamentos del neohumanismo. La pretendida "deshumanización" de la técnica tiene al mismo hombre como víctima y verdugo. El nihilismo cobra así un nuevo sentido positivo. Porque la metafísica o la modernidad interpretada desde el «Ge-stellt» es un destino del hombre que, al mismo tiempo que explica su olvido del Ser, muestra la propia impotencia del Scr para ser presencia. Este destino es algo de lo que sólo podemos «convalecer» $\mathrm{y}$ «torcers (Verwindung). De este modo, en la meditación del Ge-stellt, «la metafísica es algo que permanece en nosotros como los rastros de una enfermedad, o como un dolor al que uno se resigna".

Pero, ¿cómo pensar entonces la modernidad?: como "un largo adiós", o, desde el punto de vista de la filosofía del mañana de Nietzsche, como un «recorrer los caminos del errar inciertosen una experiencia no metafísica de la verdad que tome como modelo al arte y la retórica. Pensamiento de la fruición, del simulacro, de la apariencia no aparente. Vattimo refuerza, así, de la mano de Nietzsche, la interpretación nihilista de Heidegger. Esto es lo que separa su ontología hermenéutica de la de Gadamer, ya que piensa que ésta corre el peligro de convertirse en una filosofía de la historia de tipo sustancialmente humanista $y$, en definitiva, neokantiana. La interpretación nihilista de Vattimo consistiria en ver, en la primera época de Heidegger, el " $\mathrm{Da}$ sein» como "totalidad hermenéutica», $y$, en la segunda, la posibilidad de un pensamiento metafísico entendido como "Andenken", recuerdo.

Pero en la discusión con Gadamer aparece también otro elemento, cuyo desarrollo lleva a Vattimo a una propuesta que puede considerarse complementaria, distinta o incluso contradic- 
toria con la anterior. Advierte que en Gadamer se vuelve otra vez a la «enfermedad histórica" que ya denunciara Nietzsche, y que no es otra que el exceso de conciencia histórica que lastra la vida, la separación entre saber y hacer, entre teoria y praxis. De este modo, y junto con la propuesta ya apuntada antes de una experiencia estética y retórica, Vattimo se siente insatisfecho con los acentos fatalistas del último Heidegger, de la impotencia del hombre frente al Ser y la acción. Parece reivindicar el que, tras la disolución de la historia en la multiplicidad de los horizontes de sentido, haya la posibilidad de funda. mentar a partir de ello también la «preferencia" y la "decisión» históricas, y, en definitiva, de "cambiar las circunstancias", no quedándose en un papel de vagabundeo esteticista, o en el lamento impotente y nostálgico frente a lo que sucede alrededor.

El problema que se plantea en la propuesta de Vattimo es quién y cómo llevará a cabo esa tarea de unión entre teoría y praxis, una vez consumada la crisis de la modernidad. Vattimo no renuncia a la idea de sujeto, habla de construir un nuevo sujeto, después de haber sometido a una "cura de adelgazamienton al que nos legaron de la modernidad. Este sujeto "depotenciado" es una de las consecuencias primeras que saca de su lectura de la Carta sobre el Humanismo de Heidegger. Ahí encuentra expuesta la crisis definitiva del sujeto burgués-cristiano, el «ocaso del rol hegemónico de la conciencia" tanto respecto al sujeto, como a su acción en la historia y la sociedad. Por eso, observa también, que a partir de Ser y Tiempo van desapareciendo en Heidegger nociones emparentadas con el existencialismo, tales como las de angustia y, sobre todo, autenticidad, que asimila a tes- timonio. Reconoce que en esa obra el sujeto podía ser auténtico porque la iniciativa radicaba en él mismo, dependía de él. Bastaba con apartarse del "man" para que pudiera ser auténtico. Pero Vattimo está interesado ahora en acentuar el carácter de historicidad de la decisión: sólo es posible vivir auténticamente si el mundo es cambiado, no si uno se aparta del mundo.

Estas observaciones de Vattimo tienen dos consecuencias importantes: sobre cómo valora el compromiso político de Heidegger en relación con la "Kehre» y, más en general, qué sentido tiene hoy hablar de compromiso, o cómo debe entenderse esa posibilidad de cambiar el mundo.

Vattimo une la interpretación «interna" de la "Kehre" (producida por las propias necesidades ontológicas del pensamiento, no habría entonces fractura) y la «externa" (habria una ruptura con las lineas maestras de Ser $y$ Tiempo, ligada a su compromiso político con el nazismo). Pretende así conciliar la autointerpretación de Heidegger con las críticas de Lukács, Loewith y Adorno. Según ello, Heidegger habría continuado su crítica primera al trascendentalismo del sujeto (en sus versiones fenomenológica y neokantiana) con el análisis de su fundamento, el ocaso del individuo burgués-cristiano, indicando que, en la sociedad e historia actuales, el tema exige un nuevo ámbito de tratamiento, puesto de manifiesto en una investigación más originaria del lenguaje: es el ámbito del destino o del Ser, de unos poderes e instancias suprapersonales frente a las cuales se encuentra impotente el individuo.

El haber reconocido esto significaría el verdadero sentido y mérito del "giro" heideggeriano. Aunque todavía encuentra en él restos de pensamiento metafísico, que le impiden concebir que, des- 
pués de la muerte del sujeto, todavía pueda quedar el hombre y tener una capacidad de iniciativa, en vez de dejarla toda al Ser, lo que conduciría a un pesimismo histórico. Por el contrario, Vattimo subraya que no es posible una existencia auténtica en un mundo inauténtico, y que no debe incorporarse -a diferencia de Heidegger - la inautenticidad y el olvido dentro de la esfera del Ser. Hace falta una "nueva época del Ser», pero el individuo puede hacer algo más que esperarla o prepararla en silencio. Para ello es necesario un cambio de perspectiva, o mejor, según Vattimo, un complemento. Reconocer que el ocaso del sujeto no es sinónimo de muerte del hombre, pero éste no debe ser ya concebido meramente como individuo (con lo que se reproducirian las paradojas del sujeto burgués), sino como clase, individuo en sociedad. De este modo, Vattimo enlaza la reflexión sobre el circulo hermenéutico con la tercera de las tesis marxianas sobre Feuerbach: papel decisivo de las circunstancias, pero éstas también pucden ser cambiadas. No hay más desarrollo, hasta el momento y que yo sepa, del cómo sería posible ese nuevo y «más auténtico existir del hombre", en cuanto clase que protagoniza la historia, remitiéndose a modo de indicación al "Principio de esperanza" de Bloch.

La propuesta de Vattimo no deja de ser sugerente y extraña a la vez, porque Bloch, como es sabido, ya desde el comienzo erige el «principio de esperanza» frente al de angustia, miedo y nihilismo, que identifica con Heidegger, y que lejos de ser una crítica al sujeto burgués, se revelaría como su reflejo actual. Bloch piensa que se trata de una vieja sociedad en decadencia y de una clase social en retirada (habría que matizarlo con el análisis sobre los neoconservadores), que reflejan su propia agonía en categorías ontológicas. Donde sí hay evidencia de un punto de contacto es en la teoria del «excedente cultural", que permite clarificar y realizar la utopía concreta, encerrada en lo todavía no consciente o no llegado a ser, de los sueños diurnos de la humanidad sufriente y expectante. No es difícil en su reapropiación neoidealista encontrar un paralelismo con la destrucción y superación heideggerianas. Pero el término no es el mismo, y la ontología decisionista y materialista histórica de Bloch, fundada en el «novum» del «totum» en avance hacia el presente, poco tiene que ver con un pensamiento preparatorio o débil, que ha roto con esas categorías presuntamente exclusivas de la modernidad. Y todavía menos con el optimismo militante, no ya del marxismo frío, sino del marxismo cálido que aspira a un cambio de las circunstancias.

Aunque es aquí donde precisamente se sigue planteando el problema. Cuando Bloch se pregunta qué hace un burgués como tú en un partido comunista como éste, las expectativas de cambio de conciencia de clase se centran fundamentalmente en el interés ético superior provocado por el aumento de conocimiento. $\mathrm{Y}$, ¿dónde está y cuál es la clase que provocará el cambio de las circunstancias, que posibilitará la aparición de otro pensamiento? Es también el problema del hueco que deja el sujeto del compromiso o testimonio en Vattimo, rechazados como anacrónicos o neoexistencialistas, la razón del injerto HeideggerBloch, pero sin que sigan sin concretarse los deseos de no dejarlo todo a la actuación escatológica de la historia del Ser. 
Cuando Heidegger da la noticia de su «Kehre" en el pensamiento, también ha comenzado la de la Teoría Crítica. Hay afinidades y diferencias. En ambos casos, tiene lugar de una manera paulatina, más acentuada en el uno, quizá por su mismo anuncio, y más desapercibida en la otra, hasta que las circunstancias lo ponen de manifiesto. En la Teoría Crítica, la evolución viene dada por su propia mediación social e histórica, no por el pensamiento y lo que debe ser pensado. Hay un hilo común, y es la crítica de la razón instrumental, el análisis negativo de la época actual, que se reconoce metafísicamente como necesaria. La raíz se descubre en una dialéctica de la modernidad y de la Ilustración en la que los extremos de la reflexión crítica sobre la sociedad de masas, y la industria cultural como legados suyos, dejan al decir de Habermas, poco margen de recuperación de la modernidad.

La crítica de Horkheimer a Heidegger iba englobada en la más general a la metafísica, mientras que en Adorno era a ese tipo de metafísica; posteriormente, se centrará justamente en la acusación de abandono de la metafísica y en la imposibilidad de toda forma de trascendencia no categorizable. En la denuncia de la inadecuación del pensar al Ser, su quietismo bajo la forma de la correspondencia, han visto siempre una adaptación a lo existente, una asimilación del Ser al Poder. La palabra "destino", expresión de fuerzas elementales y originarias, se encarnaría históricamente en formas de poder, tanto más poderosas cuanto más cercanas estuvieran a su origen zoológico y plutoniano.

Una de las líneas que permanecen a lo largo de la evolución de la Teoría Crítica es la postura de Horkheimer respecto al Humanismo. En 1938, analiza el Humanismo escéptico de Montaigne y las propuestas neohumanistas que van apareciendo. Las reflexiones de los años cincuenta se reafirman en lo antes expuesto. Hay una oposición al $\mathrm{Hu}$. manismo neoplatónico en la medida que su teoría de la dignidad del hombre está desconectada con la historia, o más bien, sirve a una determinada escritura de la historia, la burguesa; también por la imposibilidad de expresar la esencia del hombre en esos térmi. nos, en una sociedad de transición que muestra lo contrario, una existencia inauténtica. No es extraño, pues, su interés por el Humanismo escéptico, en particular su talante crítico frente a lo existente. Pero ya entonces, como después, Horkheimer notará que convertir en un absoluto teorético la indignidad del hombre lleva, por la vía del nihilismo, a las mismas consecuencias que el otro tipo de Humanismo, a la complicidad con lo existente.

Frente a ellos, destacará un aHumanismo activo", ya que "no hay $\mathrm{Hu}$ manismo sin una clara toma de postura frente a los problemas históricos de la época; el Humanismo no puede existir como mera confesión de sí mismo». Y es que detecta el mismo subjetivismo en el neoplatónico que en el escéptico. Lo que les lleva a la insensibilidad social y a la desconexión con el presente histórico, es decir, a convertir ideas como la libertad, justicia o felicidad en ideales de imposible realización. El "Humanismo activo» era entendido entonces por Horkheimer como una filosofía política centrada en la crítica de la economía política. El liberalismo burgués iniciaba fórmulas de sistema capitalista que luego, en virtud de sus propias exigencias internas, desembocarian en el fascismo.

El neohumanismo se le aparecía como una confusa amalgama de elementos ideológicos, en la que toda la tradición cultural y política estaba representada 
para que todos tuvieran algo: religión, liberalismo, socialismo, ciencia y literatura, en un trasfondo ontológico existencialista. A este tema era muy sensible Horkheimer, pero particularmente a partir de los años cincuenta. Porque ya no hace una lectura del liberalismo exclusivamente en términos económi$\cos , y$, por otra parte, no tiene inconveniente en declarar "ya no somos marxistas». La recuperación tiene lugar por el contraste crítico con los ideales culturales de la tradición liberal burguesa. El idealismo mantendría como elemento válido la protesta que recorre sus creaciones frente a la injusticia de lo existente. Pero habria también que salvar al individuo, ya no desde una perspectiva de clase, sino desde el motor reformista de los ideales neoilustrados. A la petición de que cuando se hable de libertad, hay que precisar de qué libertad se está hablando, para no caer en una utopía estéril y, a la postre, conformista, se une la necesidad en Horkheimer de darle una cierta fundamentación en la nostalgia y anhelo de una religión, un Dios, encarnación de la sociedad justa. El Humanismo permanecería como análisis de lo inhumano en una sociedad injusta, como "negación determinada», pero no como escepticismo o glorificación respecto a las posibilidades de lo humano, sino como deseo de algo mejor y distinto, como solidaridad en el sufrimiento y en la búsqueda de una sociedad más racional y menos planificada.
La última fase de la Teoría Crítica, tanto en la mística judía de Horkheimer como en la estética de la trascendencia de Adorno, tiene indudables, y para algunos indeseables, puntos en común con Heidegger. La colaboración que no fue posible en vida, por la distancia y la crítica, se realiza ya a través de los mediadores. Por eso, la sugerencia de Vattimo es aceptada por aquéllos que ven una línea truncada a partir de la formulación de la Teoría Crítica, y que pudo ser retomada en $E l$ principio de esperanza de Bloch. No obstante, me parece que más allá de la coincidencia en determinados análisis filosóficos, truto de un compartido neoidealismo, hay una diferencia entre la Teoría Crítica y Heidegger. Diferencia que, por utilizar la conocida expresión de Aranguren, podríamos denominar de "talante». Heidegger ha insistido en ello a raíz de sus interpretaciones de Nictzsche, y constituye uno de los elementos más significativos de la «Kehre» y de la polémica en torno al Humanismo: se trata de colocarse ante la «decisión" de por el hombre o por el Ser.

Cuando se intenta una reformulación de la Teoría Crítica, que tenga en cuenta la mediación social e histórica de los años sesenta y comienzos de los setenta, ¿sigue siendo válida la convicción de Horkheimer en 1938: "O bien desenmascara la situación histórica o no concierne sino a los epígonos amantes de la belleza»? 